\title{
Profound hypothermia compared with moderate hypothermia in repair of acute type $A$ aortic dissection
}

\author{
Khaled D. Algarni, MD, MHSc, FRCSC, ${ }^{\mathrm{a}, \mathrm{b}}$ Bobby Yanagawa, MD, PhD, ${ }^{\mathrm{b}}$ Vivek Rao, MD, PhD, FRCSC, ${ }^{\mathrm{b}}$ and \\ Terrence M. Yau, MD, MSc, FRCSC ${ }^{\mathrm{b}}$
}

Objective: To determine the impact of the degree of hypothermia on surgical outcomes in patients undergoing repair of acute type A aortic dissection.

\begin{abstract}
Methods: Between 1990 and 2010, 211 consecutive patients underwent surgical repair of type A aortic syndrome. Patients with acute type A dissection $(n=128)$ were included. Circulatory arrest with profound hypothermia $\left(\mathrm{PH} ;<20^{\circ} \mathrm{C}\right)$ was used in 75 patients $(58.6 \%)$ and circulatory arrest with moderate hypothermia $\left(\mathrm{MH} ; 22-28^{\circ} \mathrm{C}\right)$ in 53 patients $(41.4 \%)$. Subacute or chronic dissections, intramural hematoma and penetrating aortic ulcers were excluded.
\end{abstract}

\begin{abstract}
Results: Preoperative acute kidney injury was higher in the PH group $(18.9 \%$ vs $5.3 \%, P=.01)$. Axillary or direct aortic cannulation was more prevalent in the $\mathrm{MH}$ group $(33.9 \%$ vs $11.1 \%, P=.01)$. The duration of circulatory arrest was $25.9 \pm 14.3$ and $28.9 \pm 19.9$ minutes in the $\mathrm{MH}$ and $\mathrm{PH}$ groups, respectively $(P=.3)$. The composite outcome of mortality, low cardiac output syndrome or stroke was higher in the PH group (52.8\% vs $24 \%, P<.001)$. Cardiopulmonary bypass time and blood transfusion were significantly higher in the $\mathrm{PH}$ group $(P=.04)$. By multivariable analysis $(\mathrm{C}=0.80)$, $\mathrm{PH}$ (odds ratio $[\mathrm{OR}], 7.6 ; 95 \%$ confidence interval [CI], 3.0-21.1) and preoperative shock (OR, 3.5; 95\% CI, 1.3-10.1) were independent predictors of the composite outcome.

Conclusions: MH was independently associated with a lower risk of a composite outcome of mortality and major adverse cardiac and cerebrovascular events during repair of acute type A dissection. Use of moderate hypothermic circulatory arrest avoids the detrimental effects of $\mathrm{PH}$ without an increase in the risk of neurologic injury in this study. (J Thorac Cardiovasc Surg 2014;148:2888-94)
\end{abstract}

See related commentary on pages $2894-5$.

Surgical repair of acute type A aortic dissection (AAD) is associated with a high perioperative mortality, ranging from $8 \%$ to $25 \%{ }^{1-3}$ Recent data from the International Registry of Acute Aortic Dissection (IRAD) reported an overall mortality of $25 \% .^{3}$

Deep hypothermic circulatory arrest (DHCA) has been widely used with or without adjunctive cerebral perfusion and is considered by many experts to be the standard of care for surgical repair of AAD. ${ }^{4-9}$ However, because of the potential side effects of the prolonged duration of

\footnotetext{
From the King Saud University, ${ }^{a}$ Riyadh, Saudi Arabia; and Peter Munk Cardiac Center, ${ }^{\mathrm{b}}$ Toronto General Hospital, University of Toronto, Toronto, Ontario, Canada. Disclosures: Vivek Rao reports consulting fees from CorMatrix and Medtronic; lecture fees from CorMatrix, Medtronic, and Thoratec; and equity ownership in CorMatrix. All other authors have nothing to disclose with regard to commercial support.

Received for publication Sept 22, 2013; revisions received Jan 2, 2014; accepted for publication Jan 17, 2014; available ahead of print Feb 22, 2014.

Address for reprints: Terrence M. Yau, MD, MSc, FRCSC, Peter Munk Cardiac Center, Division of Cardiovascular Surgery, Toronto General Hospital, 4N-470, 200 Elizabeth St, M5G 2C4, Toronto, Ontario, Canada (E-mail: khaled.algarni@ utoronto.ca).

$0022-5223 / \$ 36.00$

Copyright (c) 2014 by The American Association for Thoracic Surgery

http://dx.doi.org/10.1016/j.jtcvs.2014.01.020
}

cardiopulmonary bypass (CPB) usually associated with profound hypothermia $(\mathrm{PH})$, there has been increasing interest in performing aortic arch surgery using warmer temperatures with selective antegrade cerebral perfusion (SACP). ${ }^{10-13}$

Avoiding PH is associated with a reduction in CPB times, postoperative bleeding, blood transfusion, endothelial dysfunction, neuronal apoptosis, and postoperative pulmonary complications. ${ }^{14-18}$

Studies in animal models showed that brain oxygen consumption decreases by $50 \%$ of baseline at $28^{\circ} \mathrm{C}$ of core temperature. Further cooling does not decrease brain oxygen consumption efficiently. ${ }^{19}$ Moreover, profound hypothermia induces vasoconstriction and decreases the regional cerebral blood flow under SACP compared with mild or moderate degrees of hypothermia. ${ }^{20}$

Although several reports have shown the safety of moderate and profound hypothermic circulatory arrest with SACP in repair of AAD, ${ }^{4-16}$ to our knowledge, there have been no studies directly comparing moderate hypothermic circulatory arrest $(\mathrm{MH})$ with profound hypothermic circulatory arrest $(\mathrm{PH})$ in repair of AAD while accounting for the confounding effect of comorbidities, cannulation techniques, adjunctive cerebral perfusion strategies, and other confounders. 

Abbreviations and Acronyms
$\begin{array}{ll}\mathrm{AAD} & =\mathrm{A} \text { aortic dissection } \\ \mathrm{CA} & =\text { circulatory arrest } \\ \mathrm{CPB} & =\text { cardiopulmonary bypass }\end{array}$
DHCA $=$ deep hypothermic circulatory arrest
ICU = intensive care unit
IRAD = International Registry of Acute Aortic Dissection
LCOS = low cardiac output syndrome
MACCE $=$ major adverse cardiac and cerebrovascular events
$\mathrm{MH}=$ moderate hypothermia
$\mathrm{PH}=$ profound hypothermia
SACP $=$ selective antegrade cerebral perfusion

In our unit, there has been a gradual shift toward $\mathrm{MH}$ for repair of AAD over the past 2 decades. The purpose of this study was to compare clinical outcomes in patients who underwent repair of AAD under circulatory arrest using $\mathrm{PH}$ versus $\mathrm{MH}$.

\section{METHODS \\ Patient Data}

Clinical, operative, and outcome data were collected prospectively for all consecutive patients with type A dissection between 1990 and 2010 $(\mathrm{n}=211)$ at a single institution (Toronto, Canada). To have a homogenous population, we only included patients with acute AADs $(n=128)$. Patients with subacute and chronic type A dissections, intramural hematomas, penetrating aortic ulcers, and traumatic aortic transection were excluded $(\mathrm{n}=83)$. The patient population was divided into profound hypothermia $(\mathrm{PH} ; \mathrm{n}=53,41.4 \%)$ and moderate hypothermia $(\mathrm{MH} ; \mathrm{n}=75,58.6 \%)$ cohorts. $\mathrm{PH}$ was defined as circulatory arrest at a temperature less than $20^{\circ} \mathrm{C}$ (mean temperature $\left.18 \pm 0.5^{\circ} \mathrm{C}\right)$ and $\mathrm{MH}$ as a temperature of 22 to $28^{\circ} \mathrm{C}(24$ $\left.\pm 1.8^{\circ} \mathrm{C}\right)$. In the $\mathrm{MH}$ group, 2 patients $(2.7 \%)$ were not within the 22 to $28^{\circ} \mathrm{C}$ range. The lowest temperature was $21^{\circ} \mathrm{C}$ in one patient and $30^{\circ} \mathrm{C}$ in the other patient. This study was approved by our Institutional Research Ethics Board and individual consents were waived.

The primary outcome was a composite outcome of major adverse cardiac and cerebrovascular events (MACCE) defined as death, stroke, or low cardiac output syndrome (LCOS) during the index hospitalization. LCOS was included in the composite end point because in our study, LCOS was associated with high mortality and morbidity (unadjusted mortality $>40 \%$ in this cohort). A composite end point was used to increase the power of the study because the sample size was limited.

Myocardial infarction was not included in the MACCE composite outcome because it was not well defined in our database. Our database defined perioperative myocardial infarction as new $\mathrm{Q}$ waves on the electrocardiogram after surgery but we did not have complete data on myocardial infarction biomarkers.

LCOS was diagnosed if the patient required an intra-aortic balloon pump in the operating room (to be weaned from CPB) or in the intensive care unit because of hemodynamic compromise. LCOS was also diagnosed if the patient required inotropic support (dopamine, dobutamine, milrinone, or epinephrine) to maintain a systolic blood pressure greater than $90 \mathrm{~mm}$ $\mathrm{Hg}$ and cardiac index greater than $2.2 \mathrm{~L} / \mathrm{min} / \mathrm{m}^{2}$ in the intensive care unit, after optimizing preload and afterload and correction of all electrolyte and blood gas abnormalities. Patients who required a renal dose of dopamine $(\leq 3 \mu \mathrm{g} / \mathrm{kg})$ were not considered to have LCOS. Patients who received vasoconstricting medications to increase peripheral vascular resistance in the presence of normal or high cardiac outputs $\left(\geq 2.5 \mathrm{~L} / \mathrm{min} / \mathrm{m}^{2}\right)$ were also not considered to have LCOS.

\section{Anesthetic and Operative Management}

Arterial cannulation was initiated by exposing the right or left femoral artery, right axillary artery, or directly through the aortic arch, the latter generally only in patients with DeBakey type II dissections. Right axillary cannulation was performed with an 8-mm Dacron graft sewn in an end-toside fashion to the axillary artery using a running 6-0 polypropylene suture. The graft was cannulated with a 22-Fr arterial cannula (Medtronic Inc, Minneapolis, Minn) or, using a connector, directly to the arterial line. Venous cannulation was performed with a dual stage venous cannula through the right atrial appendage. $\mathrm{CPB}$ and systemic cooling were initiated and once the heart fibrillated, a vent was placed into the left ventricle via the right superior pulmonary vein.

On reaching the goal nasopharyngeal temperature, the pump was switched off and the patient was drained. The dissected aorta and the primary tear were resected. In patients with an intimal tear in the arch or proximal descending thoracic aorta, the transverse arch was replaced. Otherwise, a hemiarch replacement was performed.

In patients in whom right axillary artery cannulation was performed, the innominate artery was clamped proximally and cerebral perfusion was initiated at $18^{\circ} \mathrm{C}$ at a rate of $10 \mathrm{~mL} / \mathrm{kg} / \mathrm{min}$ to maintain the right radial pressure between 50 and $60 \mathrm{~mm} \mathrm{Hg}$. In patients who had femoral cannulation or direct aortic cannulation, cerebral protection was achieved either by antegrade perfusion through the innominate artery at similar flow rates, or retrograde perfusion via the superior vena cava. When unilateral antegrade cerebral perfusion was used, this was done through the innominate artery to perfuse the right common carotid artery. The left common carotid artery and the left subclavian artery were occluded with tourniquets during antegrade cerebral perfusion. Bilateral antegrade cerebral perfusion was used rarely. On completion of the circulatory arrest period, deairing was performed, CPB was resumed at full flow rates and systemic rewarming was initiated.

In most cases, cardioplegia was not given until after completion of the distal aortic anastomosis. At that point, myocardial arrest was achieved with cold blood cardioplegia delivered in an antegrade manner in most of the patients and retrograde cardioplegia in a minority. There was a trend toward higher use of combined antegrade and retrograde cardioplegia in the PH group compared with the MH group (11.3\% and 4\%, respectively, $P=.3$ ). During the rewarming period, proximal aortic procedures as well as any coronary or valve interventions were completed. After separation from CPB, heparin was neutralized with protamine sulfate $(1 \mathrm{mg} / 100$ $\mathrm{U}$ of heparin). During the timeframe of this study, there were multiple antifibrinolytics used, including $\varepsilon$-aminocaproic acid, tranexamic acid, and aprotinin. Data specifically on aprotinin use were not available for analysis.

\section{Statistical Analysis}

Statistical analyses were performed using SPSS 19 (IBM, Somers, NY). Univariate analyses were performed with the $\chi^{2}$ or Fisher exact test for categorical variables, Student $t$ test for normally distributed continuous variables, and the Mann-Whitney test for continuous variables with nonparametric distribution. Data are presented as medians with interquartile ranges (IQR) or means with standard deviations. Variables with a univariate $P<.25$ or those of known clinical importance were submitted to the final multivariable stepwise logistic regression model to calculate factor-adjusted odds ratios (ORs)

The following 26 variables (Tables 1 and 2) were considered as potential confounders and accounted for in the stepwise multivariable model: age (years), gender, hypertension, diabetes mellitus, angina, preoperative hemodynamic instability (shock), preoperative kidney injury, congestive heart failure, left ventricular function, peripheral vascular disease, chronic obstructive pulmonary disease, myocardial infarction, transient ischemic attack or stroke, era of surgery, DeBakey type (I vs II), 
TABLE 1. Clinical characteristics in 128 patients undergoing acute AAD repair

\begin{tabular}{|c|c|c|c|}
\hline Variable & $\begin{array}{c}\text { Moderate } \\
\text { hypothermia }\end{array}$ & $\begin{array}{c}\text { Profound } \\
\text { hypothermia }\end{array}$ & $\begin{array}{c}P \\
\text { value }\end{array}$ \\
\hline Number of patients & 75 & 53 & \\
\hline Age $(y \pm S D)$ & $60.6 \pm 14.3$ & $60.5 \pm 12$ & .95 \\
\hline $70 \mathrm{y}$ and older, n (\%) & $21(28)$ & $14(26.4)$ & .76 \\
\hline Mean BSA, $\mathrm{m}^{2} \pm \mathrm{SD}$ & $1.89 \pm 0.54$ & $1.93 \pm 0.23$ & .63 \\
\hline \multicolumn{4}{|l|}{ DeBakey type, n (\%) } \\
\hline I & $62(82.6)$ & $51(96.2)$ & .02 \\
\hline II & $13(17.3)$ & $2(3.8)$ & \\
\hline Female, n (\%) & $21(28)$ & $13(24.5)$ & .66 \\
\hline Diabetes mellitus, $\mathrm{n}(\%)$ & $7(9.3)$ & $4(7.5)$ & .72 \\
\hline Hypertension, n (\%) & $44(58.7)$ & $34(64.2)$ & .33 \\
\hline Hyperlipidemia, n (\%) & $20(26.7)$ & $11(20.8)$ & .42 \\
\hline \multicolumn{4}{|l|}{ Angina, n (\%) } \\
\hline Stable & $6(8)$ & $3(5.7)$ & .93 \\
\hline ACS & $10(13.3)$ & $7(13.2)$ & \\
\hline Shock, n (\%) & $21(28)$ & $15(28.3)$ & .70 \\
\hline Congestive heart failure, $\mathrm{n}(\%)$ & $39(29.3)$ & $18(34)$ & .36 \\
\hline \multicolumn{4}{|l|}{ LVEF, n (\%) } \\
\hline$\geq 40 \%$ & $70(93.3)$ & $47(88.7)$ & .35 \\
\hline$<40 \%$ & $5(6.7)$ & $6(11.3)$ & \\
\hline Preoperative stroke/TIA, n (\%) & $8(10.7)$ & $7(13.2)$ & .21 \\
\hline Preoperative AKI, n (\%) & $4(5.3)$ & $10(18.9)$ & .02 \\
\hline $\begin{array}{l}\text { Mesenteric/limb malperfusion, } \\
\mathrm{n}(\%)\end{array}$ & $5(6.7)$ & $6(11.3)$ & .30 \\
\hline Mesenteric & $2(2.7)$ & $3(5.7)$ & .39 \\
\hline Limb & $3(4)$ & $4(7.5)$ & .4 \\
\hline $\begin{array}{l}\text { Peripheral vascular disease, } \\
\mathrm{n}(\%)\end{array}$ & $11(14.7)$ & $8(15.1)$ & .57 \\
\hline COPD, n $(\%)$ & $2(2.7)$ & 0 & .34 \\
\hline Marfan syndrome, n (\%) & $4(5.3)$ & $2(3.8)$ & .30 \\
\hline $\begin{array}{l}\text { Preoperative hemoglobin, } \\
\mathrm{g} / \mathrm{L} \pm \mathrm{SD}\end{array}$ & $126 \pm 11$ & $128 \pm 15$ & .50 \\
\hline \multicolumn{4}{|l|}{ Era of surgery, n (\%) } \\
\hline $1990-1999(\mathrm{n}=62)$ & $34(54.8)$ & $28(45.2)$ & \\
\hline $2000-2010(n=66)$ & $34(65.2)$ & $23(34.8)$ & \\
\hline
\end{tabular}

$S D$, Standard deviation; $B S A$, body surface area; $A C S$, acute coronary syndrome; $L V E F$, left ventricular ejection fraction; $T I A$, transient ischemic attack; $A K I$, acute kidney injury; $C O P D$, chronic obstructive pulmonary disease.

concomitant coronary artery bypass graft, concomitant transverse arch procedure, concomitant aortic root procedure, cannulation strategy, cerebral perfusion strategy, surgeon, duration of circulatory arrest (minutes), mesenteric/limb malperfusion, blood transfusion, cardioplegia technique, and degree of hypothermia ( $\mathrm{PH}$ vs $\mathrm{MH}$ ). $\mathrm{CPB}$ time was included in the model but there was a high correlation between CPB time and circulatory arrest time resulting in collinearity as indicated by a high variance inflation factor for both variables when they were included together in the same model. Therefore, we dropped the CPB variable from the final model to avoid collinearity. However, because CPB time is a potential confounder of the composite outcome, we created a second multivariable model that includes CPB time. CPB did not emerge as an independent predictor of the composite outcome.

Model discrimination was evaluated by the area under the receiver operator characteristic curve, and calibration was assessed with the HosmerLemeshow goodness-of-fit statistic. Model validation was performed with bootstrapping (1000 samples). The model was evaluated for multicollinearity using the variance inflation factor.
TABLE 2. Operative and postoperative details in 128 patients undergoing acute type $\mathrm{A}$ aortic dissection repair

\begin{tabular}{|c|c|c|c|}
\hline Variable & $\begin{array}{c}\text { Moderate } \\
\text { hypothermia } \\
(\mathbf{n}=\mathbf{7 5})\end{array}$ & $\begin{array}{c}\text { Profound } \\
\text { hypothermia } \\
(\mathbf{n}=\mathbf{5 3})\end{array}$ & $\begin{array}{c}P \\
\text { value }\end{array}$ \\
\hline \multicolumn{4}{|l|}{ Operative data } \\
\hline \multicolumn{4}{|l|}{ Arterial cannulation, n (\%) } \\
\hline Femoral & $50(66.7)$ & $47(88.7)$ & .03 \\
\hline Axillary & $12(16)$ & $4(7.5)$ & \\
\hline Direct aortic & $13(17.3)$ & $2(3.8)$ & \\
\hline \multicolumn{4}{|l|}{ Cerebral perfusion, $\mathrm{n}(\%)$} \\
\hline Antegrade & $15(20)$ & $7(13.2)$ & .2 \\
\hline Retrograde & $43(57.3)$ & $30(56.6)$ & .4 \\
\hline CPB time (min) & & & .03 \\
\hline Mean \pm SD & $159 \pm 71$ & $174 \pm 60$ & \\
\hline Median (IQR) & $140(109-190)$ & $160(130-191)$ & \\
\hline Crossclamp time (min) & & & .4 \\
\hline Mean \pm SD & $90 \pm 59$ & $89 \pm 44$ & \\
\hline Median (IQR) & $75(51-120)$ & $81(58-115)$ & \\
\hline Circulatory arrest (min) & & & .06 \\
\hline Mean \pm SD & $25 \pm 13$ & $29 \pm 15$ & \\
\hline Median (IQR) & $23(19-31)$ & $29(22-35)$ & \\
\hline Lowest systemic temperature $\left({ }^{\circ} \mathrm{C}\right)$ & $24 \pm 1.8$ & $18 \pm 0.5$ & .001 \\
\hline \multicolumn{4}{|l|}{ Cardioplegia technique, n (\%) } \\
\hline Antegrade & $63(84)$ & $41(77.4)$ & .3 \\
\hline Retrograde & $9(12)$ & $6(11.3)$ & \\
\hline Both & $3(4)$ & $6(11.3)$ & \\
\hline \multicolumn{4}{|l|}{ RAA, n $(\%)$} \\
\hline RAA with AV preservation & $54(72)$ & $38(71.7)$ & .7 \\
\hline Composite aortic root & $21(28)$ & $15(28.3)$ & \\
\hline Total arch replacement, n (\%) & $7(9.3)$ & $8(15.1)$ & .2 \\
\hline Concomitant CABG, n (\%) & $9(12)$ & $9(17)$ & .3 \\
\hline \multicolumn{4}{|l|}{ Postoperative data } \\
\hline $\begin{array}{l}\text { Postoperative hemoglobin, } \\
\mathrm{g} / \mathrm{L} \pm \mathrm{SD}\end{array}$ & $102 \pm 11$ & $99 \pm 12$ & .4 \\
\hline $\mathrm{pRBC}$ transfusion, units $\pm \mathrm{SD}$ & $5.7 \pm 6.0$ & $7.0 \pm 6.0$ & .04 \\
\hline Mean $\pm \mathrm{SD}$ and median $(\mathrm{IQR})$ & $5(2-7)$ & $7(5-8)$ & \\
\hline Median ventilation, h (IQR) & $31(13-72)$ & $49(17-73)$ & .5 \\
\hline Median ICU stay, h (IQR) & $86(46-144)$ & $130(53-154)$ & .04 \\
\hline Median hospital stay, d (IQR) & $10(7-19)$ & $11(6-20)$ & .7 \\
\hline
\end{tabular}

$\overline{C P B}$, Cardiopulmonary bypass; $S D$, standard deviation; $I Q R$, interquartile range; $R A A$, replacement of ascending aorta; $A V$, aortic valve; $C A B G$, coronary artery bypass graft; $p R B C$, packed red blood cells; $I C U$, intensive care unit.

\section{RESULTS \\ Patient Characteristics}

Between 1990 and 2010, 75 and 53 patients underwent repair of AAD under hypothermic circulatory arrest (CA) using $\mathrm{MH}$ and $\mathrm{PH}$, respectively. Over the duration of the study, evaluated by era (1990-1996, 1997-2003, and 20042010), the proportion of patients undergoing surgery with MH steadily increased (Figure 1).

Baseline patient characteristics are listed in Table 1. There was a greater proportion of DeBakey type I dissection $(96.2 \%$ vs $83.3 \%, P<.02)$ and lower proportion of type II dissection $(3.8 \%$ vs $16.7 \%)$ in the $\mathrm{PH}$ versus the $\mathrm{MH}$ groups. Also, there was a greater prevalence of preoperative 


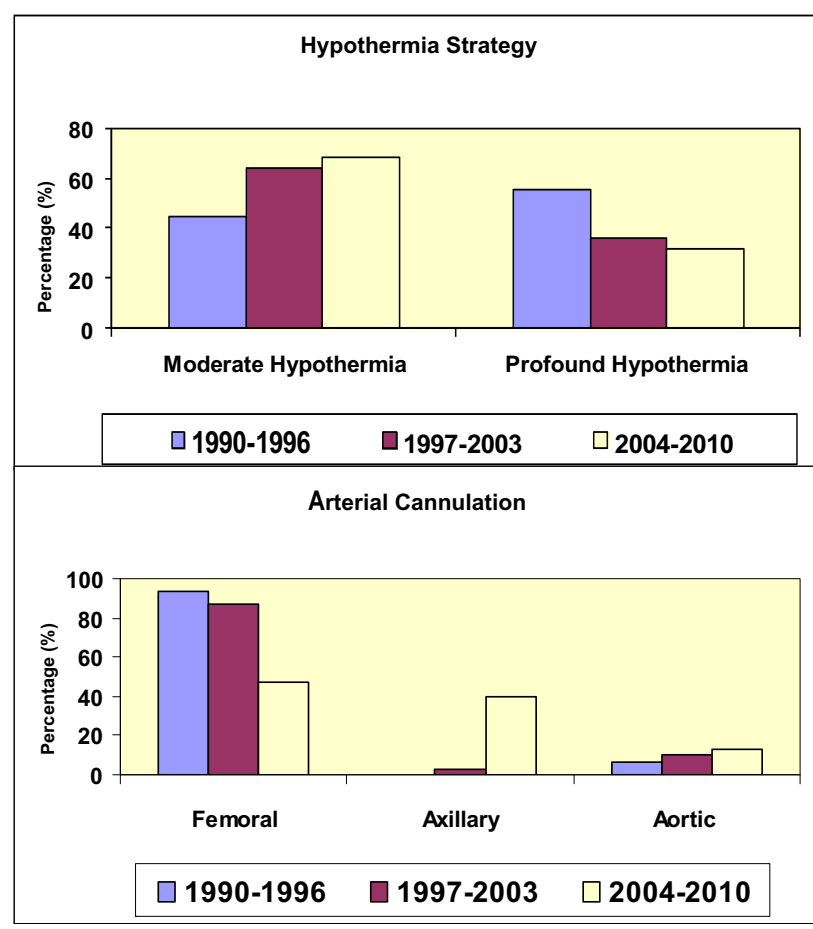

FIGURE 1. Hypothermia strategy and arterial cannulation trends for acute type A aortic dissection repair (1990-2010).

acute kidney injury in the PH cohort $(18.9 \%$ vs $5.3 \%$, $P<.02)$. Twenty-eight percent of patients in each group were hemodynamically unstable at presentation. There were no other differences in patients' preoperative characteristics including age, gender, and history of diabetes or hypertension. There was no difference between groups in left ventricular ejection fraction, preoperative shock, or a history of congestive heart failure.

\section{Perioperative and Postoperative Results}

Intraoperative variables and postoperative in-hospital outcomes are shown in Table 2.

Axillary and direct aortic cannulation were more prevalent in the MH group $(33.9 \%$ vs $11.1 \%, P=.01)$ and femoral cannulation was used in the remaining patients. Over time, the prevalence of femoral cannulation decreased, whereas the prevalence of axillary cannulation increased (Figure 1). There was no statistically significant difference between the $\mathrm{MH}$ and $\mathrm{PH}$ groups in the use of antegrade cerebral perfusion and only a minority of patients in this cohort underwent antegrade cerebral perfusion. However, because the rate of antegrade cerebral perfusion was approximately $60 \%$ higher in the MH group, the potential confounding effect of this variable was accounted for in the multivariable analysis.

The duration of CA was $25 \pm 13$ and $29 \pm 15$ minutes in the $\mathrm{MH}$ and $\mathrm{PH}$ groups, respectively $(P=.06)$.

The composite outcome of mortality and major adverse cardiac (LCOS) or cerebrovascular events (stroke) was

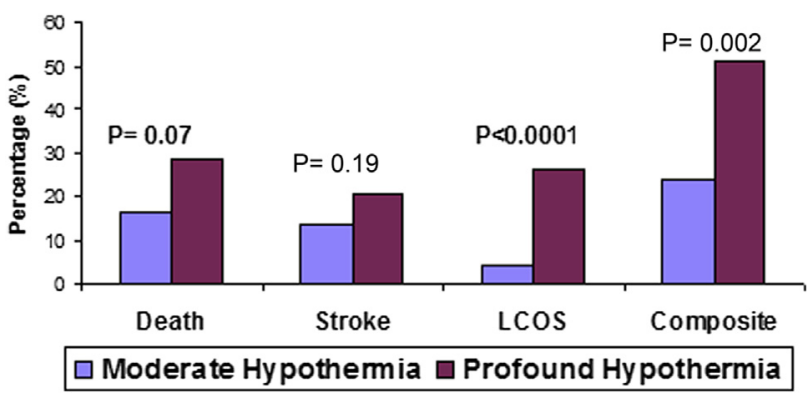

FIGURE 2. Primary outcomes for 128 patients after acute type A aortic dissection repair. $L C O S$, Low cardiac output syndrome.

markedly higher in the $\mathrm{PH}$ group $(52.8 \%$ vs $24 \%$, $P<.001$ ) (Figure 2). Differences between groups in all $3 \mathrm{com}-$ ponents of this composite outcome were noted. The composite end point of death or stroke was $24 \%$ (18 of 75$)$ and $39.6 \%$ (21 of 53) in the $\mathrm{MH}$ and $\mathrm{PH}$ groups, respectively $(P=.042)$.

Notably, only a third of all patients who received inotropes satisfied a diagnosis of LCOS and mortality among these patients was high $(30 \%)$ compared with patients who required inotropic support but did not satisfy the definition of LCOS (mortality, $12 \%$ ). There were no statistically significant differences in other outcomes including myocardial infarction, renal failure, sepsis, or atrial fibrillation, although higher trends that might carry some clinical significance were noted in the PH group (Figure 3).

\section{Resource Use}

Red blood cell transfusion requirements were higher in the $\mathrm{PH}$ group $(7.0 \pm 6.0$ vs $5.7 \pm 6.0$ units per patient; $P=.04$ ) and the mean intensive care unit (ICU) stay was longer (130 vs 86 hours, $P=.04$ ). There was no difference in overall hospital stay (Table 2).

\section{Predictors of the Composite Outcome}

By multivariable analysis $(\mathrm{C}$ statistic $=0.80)$, $\mathrm{PH}$ was an independent predictor of the composite outcome (OR, 7.6; $95 \%$ confidence interval $[\mathrm{CI}], 3-21)$. This effect of $\mathrm{PH}$ was independent of cannulation technique, cerebral perfusion strategy, CA time, era of surgery, operating surgeon, DeBakey type of aortic dissection, and extent of surgical

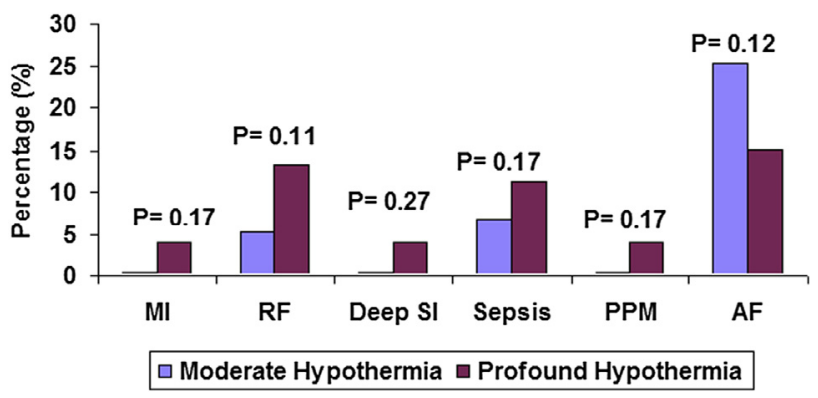

FIGURE 3. Postoperative complications for 128 patients after acute type A aortic dissection repair. $M I$, Myocardial infarction; $R F$, renal failure; $S I$, sternal infection; $P P M$, permanent pacemaker; $A F$, atrial fibrillation. 
repair among other potential confounders that were included in the model (26 variables). Preoperative shock (OR, 3.5; 95\% CI, 1.3-10) was also an independent predictor of the composite outcome. There was no evidence of multicollinearity in the model and the model was validated with bootstrapping (1000 samples).

\section{Outcomes in Elderly Patients}

Twenty-seven percent $(n=35)$ of the patients in this cohort were 70 years or older. The distribution of elderly patients ( $\geq 70$ years) was similar in the $\mathrm{MH}$ and $\mathrm{PH}$ groups ( $28 \%$ and $26.4 \%$, respectively).

There was no significant difference between the elderly $(\geq 70$ years) and the younger group in mortality $(17.1 \%$ vs $22.6 \%, P=.3)$ or $\operatorname{LCOS}(14.3 \%$ vs $14 \%, P=.7)$. However, there was a significantly higher rate of stroke in elderly patients $(28.6 \%$ vs $9.7 \%, P=.01)$. Age greater than 70 years emerged as an independent predictor of stroke (OR, $3.8 ; 95 \%$ CI, 1.4-10.6).

\section{Cause of Mortality}

The mortality in the overall cohort was $21.1 \%$ (27 patients). The most common mode of death was cardiogenic shock with multiorgan failure $(44.4 \%, \mathrm{n}=12)$. Other causes of death included massive stroke and brain death $(18.5 \%, \mathrm{n}=5)$, massive bleeding $(7.4 \%, \mathrm{n}=2)$, cardiac arrest $(7.4 \%, \mathrm{n}=2)$, septic shock $(7.4 \%, \mathrm{n}=2)$, and other causes $(14.8 \%, n=4)$, which included ruptured thoracic aneurysm $(\mathrm{n}=1)$, massive pulmonary embolism $(\mathrm{n}=1)$, mesenteric ischemia and sepsis $(\mathrm{n}=1)$, and intraoperative death due to inability to separate from CPB $(n=1)$.

\section{DISCUSSION}

In this study, 2 strategies of cooling ( $\mathrm{PH}$ and $\mathrm{MH}$ ) to repair $\mathrm{AAD}$ in a single center over 2 decades were compared. The composite outcome of death, stroke, and LCOS was higher in the $\mathrm{PH}$ group than the $\mathrm{MH}$ group $(51 \%$ and $24 \%$, respectively; $P<.001)$. The prevalence of mortality was almost 2 -fold higher in the $\mathrm{PH}$ group compared with the $\mathrm{MH}(28 \%$ and $16 \%$, respectively; $P=.07)$. Similarly, the risk of stroke with persistent neurologic deficit was $21 \%$ versus $13 \%$ in the $\mathrm{PH}$ and $\mathrm{MH}$ groups, respectively. The prevalence of LCOS was 5-fold higher in the $\mathrm{PH}$ group than in the $\mathrm{MH}$ group $(26 \%$ and $5 \%$, respectively; $P<.001$ ). The high risk of mortality and morbidity associated with repair of AAD in our study is consistent with a recent report from the IRAD group in which an overall mortality of $25 \%$ was reported.

The safety of DHCA was confirmed by several groups over the past 2 decades. Elefteriades and colleagues, Griepp and associates, and several other groups reported good results with use of DHCA with or without adjunctive cerebral perfusion. $^{2,4-9}$ However, several studies have reported detrimental effects of $\mathrm{PH}$ compared with $\mathrm{MH} .{ }^{14-20}$
Profound hypothermia is associated with longer durations of $\mathrm{CPB}$ because of the longer cooling and rewarming periods, with a potential increase in the risk of ischemicreperfusion injury. ${ }^{14,15,17}$ This may explain the higher prevalence of LCOS with PH in our study. Maganti and colleagues ${ }^{21}$ found CPB time to be an independent predictor of LCOS. Similarly, Halkos and colleagues ${ }^{11}$ found a longer CPB time with DHCA compared with moderate hypothermic $\mathrm{CA}$ in patients undergoing proximal aortic surgery including surgery for type A dissection. They attributed the higher incidence of renal failure and pulmonary complications in the $\mathrm{PH}$ group to the longer CPB time. In their study, duration of CPB was an independent predictor of mortality. Moreover, the incidence of postoperative intraaortic balloon pump use was higher in the $\mathrm{PH}$ group compared with the $\mathrm{MH}$ group in their study $(13.6 \%$ vs $6.3 \%, P=.06$ ).

Postoperative LCOS in our study was associated with an unadjusted $40 \%$ risk of mortality and a marked increase in morbidity and resource use. The poor prognosis with LCOS is not unique to patients undergoing repair of AAD. LCOS was associated with a 30 -fold increase in mortality in patients undergoing isolated mitral valve surgery ${ }^{21}$ and 38fold increase in mortality in patients undergoing isolated aortic valve surgery. ${ }^{22}$

In addition, blood transfusion requirements were significantly lower in the $\mathrm{MH}$ group than in the $\mathrm{PH}$ group in our study. Similarly, Zierer and colleagues ${ }^{10}$ found a marked reduction in mean chest tube drainage, CPB time, and ICU time in patients undergoing $\mathrm{MH}$ compared with deep hypothermia. ${ }^{10}$

The prevalence of stroke tended to be lower in the $\mathrm{MH}$ group in our study, but this difference did not reach statistical significance. Leshnower and colleagues, ${ }^{12}$ in a retrospective review of the Emory Aortic Database, compared 277 patients undergoing elective hemiarch replacement at a temperature of $28^{\circ} \mathrm{C}$ (mild hypothermia) and 233 patients at a temperature of $24^{\circ} \mathrm{C}(\mathrm{MH})$. The incidence of permanent neurologic deficit was significantly reduced in patients after mild $(2.5 \%)$ versus moderate hypothermia $(7.2 \%, P=.01)$, which was confirmed by the propensity score analysis (adjusted OR, 0.28; $P=.02$ ). In addition, several other studies reported detrimental neurologic outcomes associated with DHCA including the risk of neuronal apoptosis. ${ }^{17,18,23-25}$ In contrast, Gega and colleagues ${ }^{7}$ recently reported the safety and efficacy of DHCA as the sole means of cerebral protection in 394 consecutive patients and full preservation of cognitive abilities was found in patients with high cognitive needs. ${ }^{8}$

Although PH increases the duration of $\mathrm{CPB}$, postoperative bleeding, blood transfusion, generalized endothelial dysfunction, neuronal apoptosis, and postoperative pulmonary complications, ${ }^{14-18} \mathrm{MH}$ may not provide adequate 
protection for the spinal cord and visceral organs, especially under prolonged duration of CA. Khaladj and colleagues ${ }^{26}$ compared moderate $\left(30^{\circ} \mathrm{C}\right)$ and deep hypothermia $\left(20^{\circ} \mathrm{C}\right)$ in an animal model and reported higher levels of circulating lactate during reperfusion, indicating less effective organ protection at $30^{\circ} \mathrm{C}$ than at $20^{\circ} \mathrm{C}$. However, in their study, the CA time was 60 minutes, which is high compared with our study and most reported series. With prolonged circulatory arrest times of 45 minutes or longer, mild or moderate hypothermia may not be safe without adjunctive SACP as the linear relationship between neurologic deficit and duration of CA increases steeply after 50 minutes of CA. ${ }^{27}$ The use of adjunctive SACP increases the safe duration of $\mathrm{CA}$ under a mild to moderate degree of hypothermia. ${ }^{14,28}$

Only $4 \%$ of the patients in this study had extended CA times of 45 minutes or more. Therefore, drawing conclusions with regard to the use of deep hypothermia or moderate hypothermia in patients requiring prolonged $\mathrm{CA}$ and specifically regarding the protection of vulnerable organs, particularly the spinal cord, is not possible from our data.

We believe that nasopharyngeal temperature provides the closest approximation to brain temperature. Stone and colleagues $^{29}$ examined the accuracy of various temperature monitoring sites compared with a brain probe inserted into the cerebral cortex. Eight other body temperatures were monitored simultaneously including nasopharyngeal and bladder temperature. At the time of CA, nasopharyngeal, esophageal, and pulmonary artery mean temperatures were within $1^{\circ} \mathrm{C}$ of brain temperature with smaller mean differences than temperatures at the tympanic membrane, bladder, rectum, and other sites. Bladder temperature often lagged substantially behind nasopharyngeal temperatures by approximately $5^{\circ} \mathrm{C}$ and thus was slightly warmer during the cooling phase and significantly cooler during the warming phase.

Our study has limitations. First, this is an observational single-center retrospective study, which makes it susceptible to inherent selection and information biases. However, the prospective nature of the data collection and the low rate of missing data $(<5 \%)$ add strength to the internal validity of our study. Second, our conclusion in this study relies heavily on statistical methods to eliminate biases in patient selection and treatment, and the results should be interpreted with consideration of this limitation. We used logistic regression analysis with bootstrapping to account for confounders. Although the multivariable analysis can account for known confounders that are included in the model, it does not account for unknown confounders. Third, despite controlling for all the known confounders including the era of surgery, the effect of time is a potential confounder that may not have been adequately controlled in this study. In addition, our results do not imply causality as many unknown and subtle changes in perioperative management may have been associated with the improved results found with moderate hypothermia. ${ }^{30}$ Nonetheless, our operative techniques and postoperative management were fairly similar in both groups ( $\mathrm{PH}$ and $\mathrm{MH}$ ).

In summary, this study compared $\mathrm{PH}$ and $\mathrm{MH}$ in repair of AAD and accounted for the confounding effect of cerebral perfusion strategies, cannulation techniques, and other confounders. PH was an independent predictor of the composite outcome of death, stroke, and LCOS. This effect of PH was independent of cannulation technique, cerebral perfusion strategy, CA time, era of surgery, surgeon, and the extent of dissection and surgical repair, among other confounders included in the model (26 variables). Use of moderate hypothermic CA avoids the detrimental effect of $\mathrm{PH}$ without an increase in the risk of neurologic injury in this study. Further studies are warranted to compare $\mathrm{MH}$ versus $\mathrm{PH}$ in repair of $\mathrm{AAD}$.

\section{References}

1. Zierer A, El-Sayed Ahmad A, Papadopoulos N, Moritz A, Diegeler A, Urbanski PP. Selective antegrade cerebral perfusion and mild $\left(28^{\circ} \mathrm{C}-30^{\circ} \mathrm{C}\right)$ systemic hypothermic circulatory arrest for aortic arch replacement: results from 1002 patients. J Thorac Cardiovasc Surg. 2012;144:1042-9.

2. Fann JI, Smith JA, Miller DC, Mitchell RS, Moore KA, Grunkemeier G, et al. Surgical management of aortic dissection during a 30-year period. Circulation. 1995;92:113-21.

3. Trimarchi S, Nienaber CA, Rampoldi V, Myrmel T, Suzuki T, Mehta RH, et al International Registry of Acute Aortic Dissection Investigators. Contemporary results of surgery in acute type A aortic dissection: the International Registry of Acute Aortic Dissection experience. J Thorac Cardiovasc Surg. 2005;129: 112-22.

4. Griepp RB, Stinson EB, Hollingsworth JF, Buehler D. Prosthetic replacement of aortic arch. J Thorac Cardiovasc Surg. 1975;70:1051-3.

5. Ueda Y, Miki S, Kusuhara K, Okita Y, Tahata T, Yamanaka K. Surgical treatmen of aneurysms or dissections involving the ascending aorta and aortic arch, utilizing circulatory arrest and retrograde cerebral perfusion. J Cardiovasc Surg. 1990 31:553-8.

6. Kazui T, Kimura N, Yamada O, Komatsu S. Surgical outcome of aortic arch aneurysms using selective antegrade perfusion. Ann Thorac Surg. 1994;57: $904-11$.

7. Gega A, Rizzo JA, Johnson MH, Tranquilli M, Farkas EA, Elefteriades JA Straight deep hypothermic arrest: experience in 394 patients supports its effectiveness as a sole means of brain preservation. Ann Thorac Surg. 2007;84 759-66; discussion 766-7.

8. Percy A, Widman S, Rizzo JA, Tranquilli M, Elefteriades JA. Deep hypothermic circulatory arrest in patients with high cognitive needs: full preservation of cognitive abilities. Ann Thorac Surg. 2009;87:117-23.

9. Di Luozzo G, Griepp RB. Cerebral protection for aortic arch surgery: deep hypothermia. Semin Thorac Cardiovasc Surg. 2012;24:127-30.

10. Zierer A, Aybek T, Risteski P, Dogan S, Wimmer-Greinecker G, Moritz A. Mod erate hypothermia (30 degrees C) for surgery of acute type A aortic dissection. Thorac Cardiovasc Surg. 2005;53:74-9.

11. Halkos ME, Kerendi F, Myung R, Kilgo P, Puskas JD, Chen EP. Selective antegrade cerebral perfusion via right axillary artery cannulation reduces morbidity and mortality after proximal aortic surgery. J Thorac Cardiovasc Surg. 2009; 138:1081-9.

12. Leshnower BG, Myung RJ, Thourani VH, Halkos ME, Kilgo PD, Puskas JD, et al. Hemiarch replacement at $28^{\circ} \mathrm{C}$ : an analysis of mild and moderate hypothermia in 500 patients. Ann Thorac Surg. 2012;93:1910-5.

13. Urbanski PP, Lenos A, Bougioukakis P, Neophytou I, Zacher M, Diegeler A. Mild-to-moderate hypothermia in aortic arch surgery using circulatory arrest: a change of paradigm? Eur J Cardiothorac Surg. 2012;41:185-91.

14. Kamiya H, Hagl C, Kropivnitskaya I, Böthig D, Kallenbach K, Khaladj N, et al. The safety of moderate hypothermic lower body circulatory arrest with selective 
cerebral perfusion: a propensity score analysis. J Thorac Cardiovasc Surg. 2007; 133:501-9.

15. Mazzeffi M, Marotta M, Lin HM, Fischer G. Duration of deep hypothermia during aortic surgery and the risk of perioperative blood transfusion. Ann Card Anaesth. 2012;15:266-73

16. Harrington DK, Lilley JP, Rooney SJ, Bonser RS. Nonneurologic morbidity and profound hypothermia in aortic surgery. Ann Thorac Surg. 2004;78: 596-601.

17. Cooper WA, Duarte IG, Thourani VH, Nakamura M, Wang NP, Brown WM 3rd, et al. Hypothermic circulatory arrest causes multisystem vascular endothelial dysfunction and apoptosis. Ann Thorac Surg. 2000;69:696-702.

18. Hagl C, Tatton NA, Khaladj N, Zhang N, Nandor S, Insolia S, et al. Involvement of apoptosis in neurological injury after hypothermic circulatory arrest: a new target for therapeutic intervention? Ann Thorac Surg. 2001;72:1457-64.

19. Ehrlich MP, McCullough JN, Zhang N, Weisz DJ, Juvonen T, Bodian CA, et al. Effect of hypothermia on cerebral blood flow and metabolism in the pig. Ann Thorac Surg. 2002;73:191-7.

20. Usui A, Oohara K, Murakami F, Ooshima H, Kawamura M, Murase M. Body temperature influences regional tissue blood flow during retrograde cerebral perfusion. J Thorac Cardiovasc Surg. 1997;114:440-7.

21. Maganti M, Badiwala M, Sheikh A, Scully H, Feindel C, David TE, et al. Predictors of low cardiac output syndrome after isolated mitral valve surgery. J Thorac Cardiovasc Surg. 2010;140:790-6.

22. Maganti MD, Rao V, Borger MA, Ivanov J, David TE. Predictors of low cardiac output syndrome after isolated aortic valve surgery. Circulation. 2005;112: 448-52.
23. Kazui T, Yamashita K, Washiyama N, Terada H, Bashar AH, Suzuki T, et al. Usefulness of antegrade selective cerebral perfusion during aortic arch operations Ann Thorac Surg. 2002;74:S1806-9.

24. Reich DL, Uysal S, Sliwinski M, Ergin MA, Kahn RA, Konstadt SN, et al. Neuropsychologic outcome after deep hypothermic circulatory arrest in adults. $J$ Thorac Cardiovasc Surg. 1999;117:156-63.

25. Mendelowitsch A, Mergner GW, Shuaib A, Sekhar LN. Cortical brain micro dialysis and temperature monitoring during hypothermic circulatory arrest in humans. J Neurol Neurosurg Psychiatry. 1998;64:611-8.

26. Khaladj N, Peterss S, Pichlmaier M, Shrestha M, von Wasielewski R, Hoy L, et al. The impact of deep and moderate body temperatures on end-organ function during hypothermic circulatory arrest. Eur J Cardiothorac Surg. 2011;40: 1492-9.

27. Ergin MA, Griepp EB, Lansman SL, Galla JD, Levy M, Griepp RB. Hypothermic circulatory arrest and other methods of cerebral protection during operations on the thoracic aorta. J Card Surg. 1994;9:525-37.

28. Hagl C, Khaladj N, Karck M, Kallenbach K, Leyh R, Winterhalter M, et al. Hypothermic circulatory arrest during ascending and aortic arch surgery: the theoretical impact of different cerebral perfusion techniques and other methods of cerebral protection. Eur J Cardiothorac Surg. 2003;24:371-8.

29. Stone JG, Young WL, Smith CR, Solomon RA, Wald A, Ostapkovich N, et al. Do standard monitoring sites reflect true brain temperature when profound hypothermia is rapidly induced and reversed? Anesthesiology. 1995;82:344-51.

30. Rubin DB. The design versus the analysis of observational studies for causal effects: parallels with the design of randomized trials. Stat Med. 2007;26: 20-36.

\section{EDITORIAL COMMENTARY}

\section{Hypothermic circulatory arrest is not just about temperature}

Kevin L. Greason, MD

See related article on pages 2888-94.

The enlightened ruler is heedful, and the good general full of caution.

$$
\text { -Sun Tzu, The Art of War }
$$

In this issue of the Journal of Thoracic and Cardiovascular Surgery, Algarni and colleagues ${ }^{1}$ report improved outcomes with moderate hypothermic circulatory arrest $\left(22^{\circ} \mathrm{C}-28^{\circ} \mathrm{C}\right)$ in 75 patients undergoing acute ascending aorta dissection. Readers should be interested in this article because it directly compares outcomes of that group with 53 patients treated with profound hypothermic circulatory arrest

From the Mayo Clinic, Rochester, Minn.

Disclosures: Author has nothing to disclose with regard to commercial support.

Received for publication Sept 28, 2014; accepted for publication Sept 29, 2014

Address for reprints: Kevin L. Greason, MD, Mayo Clinic, 200 First St Southwest,

Rochester, MN 55905 (E-mail: greason.kevin@mayo.edu).

J Thorac Cardiovasc Surg 2014;148:2894-5

$0022-5223 / \$ 36.00$

Copyright (c) 2014 by The American Association for Thoracic Surgery

http://dx.doi.org/10.1016/j.jtcvs.2014.09.128 $\left(<20^{\circ} \mathrm{C}\right)$. The enlightened reader, however, will identify 3 areas of concern in this article: composite end points, surrogate variables, and overly exuberant statistical prowess.

Algarni and colleagues ${ }^{1}$ used a composite end point to increase the power of their study because the sample size was limited. This technique may be of dubious value here. ${ }^{2}$ Death is death; but there are different grades of stroke and low cardiac output syndrome. No definition of stroke is given in the study; the definition of low cardiac output syndrome may be too encompassing. Intra-aortic balloon pump therapy is one extreme end of the spectrum (ie, mechanical support); the need for inotropic support to maintain systolic blood pressure greater than $90 \mathrm{~mm} \mathrm{Hg}$ and cardiac index greater than $2.2 \mathrm{~L} / \mathrm{min} / \mathrm{m}^{2}$ may represent the other end.

Operation for acute ascending aorta dissection is associated with a significant risk of complications including bleeding, stroke, and death. The associated morbidity and mortality is related not just to the pathology of the dissection but also to the repair of the dissection with hypothermic circulatory arrest. In this article, temperature strategy is the main focus. That strategy misses the mark, however; because 